\title{
Influence of Different Doses of Irradiation on Oxidant and Antioxidant Systems in the Brain of Guinea Pigs
}

\author{
${ }^{1}$ Yildiz Guney, ${ }^{2}$ Ayse Bilgihan, ${ }^{1}$ Ayse Hicsonmez, ${ }^{3}$ Aysen Dizman, ${ }^{4}$ Candan Ozogul, \\ ${ }^{1}$ Meltem Nalca Andrieu, ${ }^{1}$ Cengiz Kurtman \\ ${ }^{1}$ Ankara University School of Medicine Department of Radiation Oncology, Ankara, Turkey \\ ${ }^{2}$ Gazi University School of Medicine Department of Biochemistry, Ankara, Turkey \\ ${ }^{3}$ Ankara Oncology Hospital, Department of Radiation Oncology, Ankara, Turkey \\ ${ }^{4}$ Gazi University School of Medicine Department of Histology, Ankara, Turkey
}

\begin{abstract}
The purpose of this study was to establish the impact of oxidative stress in the damaged brain tissue, irradiated with two different dose levels, a single dose of 8 and $15 \mathrm{~Gy}$. In addition, the histological findings caused by ionizing radiation in the early period was investigated. The levels of MDA, GSH, SOD, CAT, GSH-Px and selenium were estimated in brain tissue. For the histological examination, brain tissues were examined at photo light microscope.

MDA contents of brain after 8 Gy and 15 Gy $\gamma$-irradiation were markedly elevated compared with group 1. Brain SOD activity decreased after exposure to $15 \mathrm{~Gy} \gamma$-irradiation, there was a significant difference compared with group 1 and group 2. Brain GSH-Px activity in group 2 and group 3 was enhanced when compared with group 1. CAT activity of brain after 15 Gy $\gamma$-irradiation was markedly decreased compared with group 1 and group 2. GSH levels were significantly lower in group 2 and 3 when compared with group 1. In this study, brain selenium levels were not found to be markedly changed after irradiation. In group 3 basal membrane structure was found to be highly thicker when compared group 1 and group 2.

As a result, in the early period, high doses of ionizing radiation ( $8 \mathrm{~Gy}$ and $15 \mathrm{~Gy}$ ) influences the oxidantantioxidant system in guinea-pig brain, after the formation of LPO, antioxidant levels alter and this may play a role in reducing tissue damage caused by RT whereas the histologic changes occur when the dose is increased.
\end{abstract}

Key words: Ionizing radiation, brain, oxidative stress

\section{INTRODUCTION}

Radiation is known to produce various reactive oxygen species (ROS) in biological systems such as superoxide, hydrogen peroxide and hydroxyl radical and various types of tissue damage due to free radical reactions ${ }^{[1]}$. The range of antioxidant defences available within the cell and in the extracellular fluid should be adequate to protect against oxidative damage.

Radiation therapy (RT) is considered to be one of the most popular and important tools to cure cancer ${ }^{[2]}$. The radiosensitivity of normal tissues particularly organs away from the tumor sites are suggested to limit the therapeutic gain ${ }^{[3]}$.

Detrimental effect of ionizing radiation occurs mainly due to free radicals generated through the decomposition of cellular water ${ }^{[4]}$. However, organisms have protective systems against free radical reactions, for example, endogenous antioxidants and antioxidative enzymes.

All aerobic organisms are susceptible to oxidative stress simply because semireduced oxygen species are produced by mitocondria during respiration ${ }^{[5]}$. Brain is considered abnormally sensitive to oxidative damage ${ }^{[6]}$ and in fact early studies demonstrating the ease of peroxidation of brain membrans. Brain is enriched in the more easily oxidizable polyunsaturated fatty acids such as docosahexaenoic acid and eicosapentaenoic acid as it has a limited ability to perform aerobic glycolysis, it is unusually vulnerable to hypoxia ${ }^{[7]}$. On the other hand, brain is not enriched in antioxidant defences; it contains relatively low levels of superoxide dismutase (SOD), catalase (CAT), glutathione peroxidase $(\mathrm{GSH}-\mathrm{Px})^{[8]}$. 
It has been widely recognized that the brain tumors, such as glioblastome multiforme (GBM) is highly resistant to standard therapies such as chemotherapy and radiotherapy. However total dose should not be increased in order not to cause damage in the surrounding brain tissue in high doses. The effectiveness of RT frequently is limited by the tolerance of normal brain tissue. The pathogenesis of this damage is uncertain, and understanding the response of potential target cell population may provide information useful for developing strategies to optimize therapeutic irradiation.

Recent improvements in RT delivery systems, coupled with a better understanding of the molecular biology of normal tissue injury have resulted in more aggressive attempts to escalate radiation doses in an effort to improve the outcome for patients with GBM [9].

The purpose of this study was to test the hypothesis that radiation- induced damage on brain tissue caused by two different single dose levels of 8 and 15 Gy was mainly mediated by ROS accumulation and especially after lethal dose of 15 Gy, the cellular antioxidant capacity might be insufficient with the excess of ROS. In addition, the histological findings caused by ionizing radiation in the early period were investigated.

\section{MATERIALS AND METHODS}

Animals and irradiation: Guinea pigs weighting approximately $350 \mathrm{~g}$ were used in this study. The guniea pigs were divided into three groups each consisting of 10 animals. Group 1: Control; group 2: Irradiated with a dose of 8 Gy (single dose, whole body); group 3: Irradiated with a dose of 15 Gy (single dose, whole body). Irradiation was carried out using a ${ }^{60} \mathrm{Co}$ source.

All animal procedures were carried out according to the rules of local Ethic Committee. The animals in group 2 were exposed to a dose of 8 Gy irradiation by $\gamma$-rays of ${ }^{60} \mathrm{Co}$, with a source-axedistance (SAD) of $80 \mathrm{~cm}$ whole body following ketamine hydrochloride anesteshia. The guinea pigs in group 3 were applied to a dose of 15 Gy irradiation to the whole body following anesthesia. $24 \mathrm{~h}$ after irradiation, all animals were euthanized using ketamine hydrochloride $\left(\right.$ ketalar $^{\mathbb{B}}{ }$, Eczacibasi, Turkey). The tissues were briefly washed in ice-cold $0.9 \%$ saline $(\mathrm{w} / \mathrm{v})$, and frozen in liquid nitrogen. The tissues were stored at $-70{ }^{\circ} \mathrm{C}$ until the subsequent protein and enzyme assays

Biochemical assays: For SOD assay, tissue samples were homogenized in the ratio of $1 / 10(\mathrm{w} / \mathrm{v})$ in phosphate buffer ( $\mathrm{pH} 7.4$ ) and centrifuged at 5000 $\mathrm{g}$ for $30 \mathrm{~min}$. The supernatant was carefully separated, the $3 / 5(\mathrm{v} / \mathrm{v})$ chloroform and ethanol were added. This mixture was centrifuged at $5000 \mathrm{Xg}$ for 2 h. The supernatant was used for the determination of SOD. This assay involves xanthine oxidase used as superoxide generator ${ }^{[10]}$. The protein concentration of the same supernatant was measured by the method of Lowry ${ }^{[11]}$ and the results were expressed as unit per $\mathrm{mg}$ protein that inhibits the rate of nitroblue tetrazolium (NBT) reduction by $50 \%$.

For the determination of GSH-Px activity, tissue samples were homogenized at the ratio of $1 / 10$ $(\mathrm{w} / \mathrm{v})$ in phosphate buffer $(\mathrm{pH}$ 7.0) containing 0.5 mM EDTA and then centrifugated at $3500 \mathrm{rpm}$ for 15 min. Protein concentration of the supernatant was measured by the method of Lowry ${ }^{[11]}$ and GSH-Px activity was measured by a modification of the coupled assay procedure of Paglia and Valentine ${ }^{[12]}$. The results were expressed as nmoles oxidized NADPH per minute in per mg protein.

Tissue CAT activity was measured by the method of Aebi ${ }^{[13]}$. Tissue samples were homogenized at the ratio of $1 / 10$ (wv) in phosphate buffer ( $\mathrm{pH} \mathrm{7.0)}$ and then centrifugated at $3500 \mathrm{rpm}$ for 15 min. $\mathrm{H}_{2} \mathrm{O}_{2}$ was added to the supernatant and the decrease in absorbance was measured at $240 \mathrm{~nm}$ for $3 \mathrm{~min}$. The protein concentration of the supernatant was measured by the method of Lowry ${ }^{[11]}$. The results were expressed as $\mathrm{K} / \mathrm{mg}$ protein

.The levels malondialdehyde (MDA) were determined in tissue samples homogenized in the ratio of $1 / 10(\mathrm{w} / \mathrm{v})$ in $1.5 \%(\mathrm{w} / \mathrm{v})$ cold KCI solution, by thiobarbituric acid method ${ }^{[14]}$ and the results were obtained in $\mathrm{nmol} /$ tissue weight.

The reduced glutahione (GSH) contents of tissue samples were determined by the method of Elman et al. ${ }^{15]}$. Tissue samples were homogenized in the metaphosphoric acid solution and coloured by DTNB. The results were expressed as micromoles per mg protein.

Selenium levels were measured with atomic absorption spectrophotometry (Unicam-AAS 939). The mixture of $\mathrm{HNO}_{3} / \mathrm{HCLO}_{4}$ is used to mineralize the samples. The inclusion of $\mathrm{HCLO}_{4}$ in the digestive process is essential for conversion of organoselenium to selenium. After digesting process, selenium determination has been carried out using the hydride generation atomic absorption spectrometry (HGAAS) technique $[16,17]$. The results have been expressed as $\mathrm{ng} / \mathrm{g}$ of brain tissue.

Histology: For the histological examination of the brain; brain tissues were preserved in gluteraldehide solution for 72 hours and then washed in the phosphate buffer and preserved in propylene oxide for 30 minutes. These tissues were embedded in \% 50- \% 50 propylene oxide and araldite. Then they were stained with toluidin blue. All these tissues were examined at photo light microscope $\left(\mathrm{BH}_{2}\right.$, Olimpus, Japan).

Statistical analysis: Kruskal-Wallis (nonparametric ANOVA) test was used for the 
statistical analysis and Dunn's multiple comparison test was performed as post-hoc test. A p value $<0.05$ was considered significant.

\section{RESULTS}

The values of brain MDA, SOD, GSH-Px, CAT activities, GSH and selenium in three experimental groups are presented at Table 1.

MDA contents of brain after 8 and 15 Gy $\gamma$ irradiation were markedly elevated when compared with group $1(p<0.05$ and $p<0.001$, respectively), but there was no significant difference between groups 2 and 3.

Brain SOD activity decreased after exposure to 15 Gy $\gamma$-irradiation, there was a significant difference when compared with group 1 and group $2(p<0.01)$.
Brain GSH-Px activity in group 2 and group 3 was enhanced when compared with group 1 ( $p<0.05$ and $\mathrm{p}<0.001$, respectively). There was no difference between group 2 and group 3 .

CAT activity of brain after 15 Gy $\gamma$-irradiation was markedly decreased when compared with group 1 and group $2(\mathrm{p}<0.01)$.

Reduced GSH levels were significantly lower in group 2 and 3 when compared with group 1 ( $p$ $<0.001$ )

In this study, brain selenium levels were not found to be markedly changed after irradiation.

The brain tissues from all groups were stained with toluidin blue and examined at $\mathrm{BH}_{2}$ photo light microscope. In group 3; the thickness of the basal membrane was increased when compared group 1 and group 2 (Fig.1a-c).

Table 1:The values of brain MDA, SOD, GSH-Px, CAT activities, GSH, selenium in three experimental groups are presented at Table (mean \pm SD)

\begin{tabular}{|c|c|c|c|c|c|c|}
\hline Groups & $\begin{array}{c}\text { MDA } \\
\text { (nmol/tissue) }\end{array}$ & $\begin{array}{c}\text { SOD } \\
\text { (U/mg protein) }\end{array}$ & $\begin{array}{c}\text { GSH-Px } \\
\text { (nmol oxidized } \\
\text { NADPH/min/mg } \\
\text { protein) }\end{array}$ & $\begin{array}{c}\text { CAT } \\
(\mathrm{K} / \mathrm{mg} \text { protein) }\end{array}$ & $\begin{array}{c}\text { GSH } \\
\text { ( } \mu \mathrm{mol} / \mathrm{mg} \\
\text { protein })\end{array}$ & $\begin{array}{c}\text { Se } \\
\text { (ng/g tissue) }\end{array}$ \\
\hline Group 1 & $90.5 \pm 23.02$ & $31.41 \pm 3.61$ & $2.03 \pm 0.34$ & $0.0035 \pm 0.004$ & $0.293 \pm 0.045$ & $44.35 \pm 7.13$ \\
\hline Group 2 & $158.62 \pm 18.95^{*}$ & $31.52 \pm 3.73$ & $3.06 \pm 0.49^{* *}$ & $0.0036 \pm 0.0008$ & $0.169 \pm 0.031^{* * *}$ & $53.00 \pm 9.79$ \\
\hline Group 3 & $235.32 \pm 43.05^{* * *}$ & $24.68 \pm 2.62^{* *, * * * *}$ & $3.16 \pm 0.37^{* * *}$ & $0.0027 \pm 0.0003^{* *, * * *}$ & $0.162 \pm 0.02^{* * *}$ & $44.64 \pm 6.44$ \\
\hline
\end{tabular}
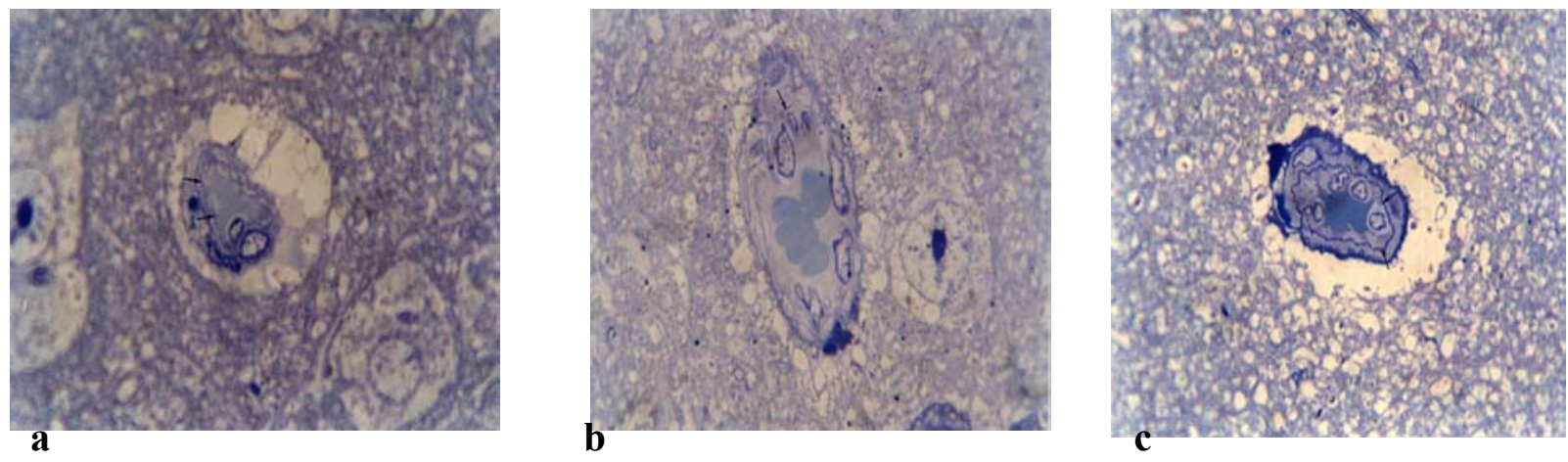

Fig 1(a, b, c): Brain tissue vessels, basal membrane. (Toluidine Blue $\times 1000$ ). (a; control group, b; 8 Gy irradiated group, c; 15 Gy irradiated group) 


\section{DISCUSSION}

The use of ionizing radiation to kill tumor cells is a common treatment of cancer. The tolerance of normal brain tissue to irradiation is the primary factor limiting the dose of 50-60 Gy in 6 weeks prolongs the median life span of patients with malign gliomas [18, 19]. Meanwhile the positive effects are generally for short duration because of the aggressive behavior of the more malignant gliomas, especially GBM and the intolerance of normal brain tissues to higher radiation doses.

One of the major reasons for cellular injury after radiation exposure is the generation of free radicals and the possible increased levels of lipid peroxides in tissues.

In the present study, no acute behavioural changes were observed in guinea pigs following irradiation. There were no deaths or obvious neurologic changes in animals that received 8 Gy or 15 Gy following irradiation in 24 hours.

In the present study, histological findings clearly show that there is no significant difference between control and irradiated groups. In group 1 and group 2, the structure of basal membrane was normal but in 15 Gy group in addition to a slight decrease in the number of astrocytes, a thickening of vascular basal membrane has been observed as a result of defence against radiation. In this present model, irradiation does not favour a role of direct damage to neurons in the early period of radiation induced brain toxicity.

Chiang et al. ${ }^{[20]}$ reported that no acute behavioural changes were observed in mice in the days following brain irradiation, although acute cellular changes were noted, similarly with our findings.

Exposure to ionizing radiation causes radiolysis of water in tissues leading to generation of ROS which are known to affect the antioxidant defence systems and induce lipid peroxidation (LPO) ${ }^{[21]}$. In this study, MDA is used as a marker of the rate of LPO which is accepted as tissue chain reaction ${ }^{[14]}$.

Whole body $\gamma$-irradiation of guinea pigs at $8 \mathrm{~Gy}$ and 15 Gy produced a significant increase in the level of brain MDA, compared with control group.

Sener et al. ${ }^{[22]}$ applied 8 Gy single whole body dose to each rat and decapitated one group at $12 \mathrm{~h}$ and second group at $72 \mathrm{~h}$ after irradiation. Liver, lung, colon and intestinal tissue levels of MDA were elevated in both groups.

Ono et al. ${ }^{[23]}$ applied 5 Gy whole body $\gamma$ irradiation the mice. All the animals were euthanized after 24 and 48 hours. They also examined the levels of MDA in the brain tissues. MDA levels were found markedly increased to the control group.

Guney et al. ${ }^{[24]}$ reported the increase of MDA after $\gamma$-irradiation at 8 and 15 Gy after 24 hours in the liver of guinea pigs.

After applying 15 Gy $\gamma$-irradiation, the activities of SOD and CAT dropped significantly when compared with control and group 2. In our observation, the significant decrease in both SOD and CAT activities after 15 Gy $\gamma$-irradiation leads to increase in the formation of $\mathrm{O}_{2}^{-}$and $\mathrm{H}_{2} \mathrm{O}_{2}$. This decline may be due to inactivation of SOD by ROS ${ }^{[25,26]}$. Moreover, the present study the decrease in the activity of CAT, which degrades hydrogen peroxide, suggests an increase in this oxygen species in irradiated brain tissue.

$24 \mathrm{~h}$ after 15 Gy $\gamma$-irradiation, the activity of CAT significantly decrease in agreement with previous observations ${ }^{[27,28]}$. RT, causes enzyme deficiencies which arise as a result of enormous production of free radicals in the system at high concentrations, hydrogen peroxide is converted to oxygen and water by CAT, which is predominantly localized in the peroxisomes ${ }^{[7]}$.

Another antioxidant enzyme, GSH-Px, markedly increased after applying 8 and 15 Gy $\gamma$-irradiation when compared with control group. GSH-Px is a defence enzyme against hydrogen peroxides and another hydroperoxides. At low concentrations, hydrogen peroxide is converted to water by the selenium containing GSH-Px. GSH-Px reduces hydrogen peroxide to respective alcohols and water with GSH as the electron donor ${ }^{[29]}$. In the present study, it may be reasonable to speculate that the observed increase in GSH-Px activity in brain after radiation exposure is one of the self- defence mechanisms against in LPO.

Kuttan et al. ${ }^{[30]}$ applied $10 \mathrm{~Gy} / 5$ fractions whole body $\gamma$-irradiation to the rats. They examined GSH-Px activity in the liver and it was found markedly increased compared to the control group.

Selenium is a trace element and is found in the structure of GSH-Px. In the present study, there was no significant difference between the selenium levels in different groups. When compared with liver, kidney and muscle, the GSH-Px activity in brain tissue is less affected, with changes in selenium levels in brain is significantly lower than the other tissues ${ }^{[31]}$.

8 and 15 Gy irradiation to the whole body caused a decrease in the levels of GSH, but there was no markedly difference between the group 2 and 3. GSH represents a key cellular defence mechanism against oxidative injury, and lowered concentrations of GSH resulting from increased formation of ROS. $\mathrm{H}_{2} \mathrm{O}_{2}$ which is produced during oxidative stress can cause extensive damage and GSH levels are greatly decreased ${ }^{[6,32]}$.

Ramadan et al. ${ }^{[33]}$ applied single-dose 6 Gy whole body $\gamma$-irradiation to the rats. They examined the levels of GSH in the liver and a significant decrease was detected. Therefore, the decline of GSH level in the brain after irradiation may be due to its consumption during the oxidative stress induced by irradiation. This was directly reported in our study, high doses $\gamma$ irradiation caused to decrease the GSH, which is known to be a free radical scavenging agent.

As a result, in the present model delivering single dose of ionizing irradiation (8-15Gy) caused the accumulation of ROS and especially after applying 15 Gy the antioxidants were not enough to eliminate ROS accumulation, in histological findings as a result of defence against this, the thickness of basal membrane was increased only after 15 Gy. 


\section{REFERENCES}

1. Adler V., Yin Z., Tew K.D. and Ronai, Z., 1999. Role of redox potential and reactive oxygen species in stress signalling. Oncogene, 18: 104-111.

2. Brock W.A. and Geara F.B, 1995. Clinical Relevance Of Normal Tissue Radiosensitivity, Radiation Research, $10^{\text {th }}$ ed. Wurzburg, ICRR, Society, Vol. II, p 843-846.

3. Agrawal A., Chandra D., Kale R.K., 2001. Radiation-induced oxidative stress: 2 studies in liver as distant organ of tumor bearing mice. Mol. Biochem., 224: 9-17.

4. Winterbourn C.C., 1993. Superoxide as an intracellular radical sink. Free Radic. Biol. Med., 14: 85-90.

5. Floyd R.A., 1992. Free radical damage to protein and DNA: Mechanisms involved and relevant observations on brain undergoing oxidative stress. Ann. Neurol., 32: 22-27.

6. Skaper S.D., Fabris M., Ferrari V., Dalle Carbonare M., and Leon A., 1997. Quercetin protects cutaneous tissue-associated cell types including sensory neurons from oxidative stress induced by glutathione depletion: cooperative effects of ascorbic acid. Free Radic. Biol. Med. 669-678.

7. Robbins M.E.C., and Zhao W., 2004. Chronic oxidative stres and radiation-induced late normal tissue injury: a review. Int. J. Radiat. Oncol. Biol. Phys. 80: 251-259.

8. Dringen R., Gutterer J.M. and Hirrlinger J., 2000. Glutathione metabolism in brain. Eur. J. Biochem. 267: 4912-4916.

9. Denham, J.W., and Hauer-Jensen M., 2002. The radiotherapeutic injury-a complex "wound." Radiother. Oncol. 63: 129-145.

10. Yi-Sun S., Oberley L.W., and Li Y.., 1988. A simple method for clinical assay of superoxide dismutase. Clin. Chem. 34: 497-500.

11. Lowry O.H., Rosenbrough N.J., and Farr A.L. 1951, Protein measurement with the folin reagent. J. Biol. Chem. 193: 265-275.

12. Paglia D.E., and Valentine W.N., 1967. Studies on quantitative and qualitative characterization of erytrocyte glutathione peroxidase. J. Labor. Clin. Med. 70: 158-169.

13. Aebi H., 1984. Catalase in vitro. Methods Enzymol.. 105: 121-126.

14. Ohkawa H., Ohishi N., and Yagi K., 1979. Assay for lipid peroxides in animal tissues by thiobarbituric acid reaction. Ann. Biochem. 95: 351-358.

15. Elman G.L., 1959. Tissue sulfidryl groups. Arch. Biochem. Biophys. 82: 70-77.

16. Lei X.G., Evenson J.K., Thompson K.M., and Sunde R.A. 1995. Glutathione peroxidase and phospholipid hydroperoxide glutathione peroxidase are differently regulated in rats by dietary selenium. J. Nutr. 125: 1438-1446.

17. Schloske I., Waldner H., and Marc F., 2002. Optimisation of sample pre-treatment in HG-AAS selenium analysis. Anal. Bioanal. Chem. 372(5-6): 700-704.

18. Miura Y., Kaunori A., and Urano S., 1997. In vivo electron parmagnetic resonanse studies on oxidative stress caused by $\mathrm{x}$-irradiation whole mice. Free Radic.Biol. Med. 23: 533-540.

19. Graf R., Hildebrand B., Tilly G., Sreenivasa G., Ullrich R., Maier-Hauff K., Felix R., and Wust P., 2005. Dose escalated conformal radiotherapy of glioblastomas-results of a retrospective comparison applying radiation doses of 60 and 70 Gy. Onkologie 28: 325-330.

20. Chiang C., Mc Bride W.H., and Withers H.R. 1993. Myelin-associated changes in mouse brain following irradiation. Radiother. Oncol. 27: 229-236.

21. Riley P.A. 1994. Free radicals in biology: Oxidative stress and the effects of ionizing radiation. Int. J. Radiat. Oncol. Biol. Phys. 65:2733.

22. Sener G., Jahovic N., Tosun O., Atasoy B.M., and Yegen B.C., 2003. Melatonin ameliorates ionizing radiation-induced oxidative organ damage in rats. Life Sci. 74: 563-572.

23. Ono S., Cai L., and Cherian M.G. 1998. Effects of gamma radiation on levels of brain metallothionein and lipid peroxidation in transgenic mice. Radiat. Res. 150: 52-57.

24. Guney Y., Bukan N., Dizman A., Hicsonmez A., and Bilgihan A., 2004. Effects of two different high doses of irradiation on antioxidant systm in the liver of guinea pigs. Eksp. Oncol. 26: 71-74.

25. Wiseman H., and Halliwell B. 1996. Damage to DNA by reactive oxygen and nitrogen species: Role in inflammatory disease and progression to cancer. Biochem. J. 313: 7-29.

26. Weiss S.L., Evenson J.K., Thompson K.M., and Sunde R.A. 1996. The selenium requirement for glutathione peroxidase level is half of the selenium requirement for glutathione peroxidase in female rats. J. Nutr. 126: 2260-2267.

27. Thresiamma K.C., George J., Kuttan R. 1996. Protective effect of curcumin, ellagic acid and bixin on ratiation induced toxicity. Indian J. Exp. Biol. 34: 845-847.

28. De A.K., Rajan R.R., Krishnamoorthy L., Bhatt M,B., and Singh B.B., 1995.Oxidative stress in radiation-induced interstitial pneumonitis in the rat. Int. J. Radiat. Biol. 68, 405-409.

29. Klotz L.O., Kroncke K.D., and Buchczyk D.P., 2003. Role of copper, zinc, selenium and tellurium in the cellular defence against oxidative and nitrosative stress. J. Nut., 133: 1448S-1451S.

30. Rekha P.S., Kuttan G., and Kuttan R., 2001. Effect of brahma rasayana on antioxidant system after irradiation. Indian J. Exp. Biol., 39: 1173- 1175.

31. Neve J., 2002. Selenium as a nutraceutical: How to conciliate physiological and supra-nutrional effects for an essential trace element. Curr. Opin. Clin. Nutr. Metab. Care. 5: 659-663.

32. Korotkina R.N., Matskevich G.N., Devlikanova A.S., Vishnevskii A.A., Kunitsyn A.G., and Karelin A.A. 2002. Activity of glutathione metabolizing and antioxidant enzymes in malignant and benign tumors of human lungs. Bull. Exp. Biol. Med. 133: 697-700.

33. Ramadan L.A., Shouman S.A., Sayed-Ahmed M.M., El-Habit O.H. 2001. Modulation of radiation induced organs toxicity by cremophor-el in experimental animals. Pharmacol. Res. 43: 185191. 